\title{
Influence of CYP2C19 genotype on antiplatelet treatment outcomes after percutaneous coronary intervention in patients with coronary heart disease
}

\author{
DONGBIAO YU, LIKUN MA, JUNLING ZHOU, LONGWEI LI, WU YAN and XIAOFAN YU \\ Department of Cardiology, The First Affiliated Hospital of USTC, Division of Life Science and Medicine, \\ University of Science and Technology of China, Hefei, Anhui 230001, P.R. China
}

Received October 25, 2019; Accepted November 27, 2019

DOI: $10.3892 / \mathrm{etm} .2020 .8592$

\begin{abstract}
The aim of the study was to compare the clinical efficacy and safety of ticagrelor and clopidogrel in patients with coronary heart disease one year after percutaneous coronary intervention (PCI), and to explore their association with the CYP2C19 gene polymorphism. A total of 971 patients with coronary heart disease who were hospitalized and underwent PCI from April 2016 to May 2017 were studied. All 971 patients were divided into three subgroups according to CYP2C19 gene types as fast metabolizing, slow metabolizing and very slow metabolizing type. Patients were also classified according to the oral antiplatelet aggregation drugs they received: clopidogrel group and ticagrelor group. The incidence of major adverse cardiac events (MACE) and bleeding events in the clopidogrel-treated and ticagrelor-treated groups and in patients with fast, slow, and very slow CYP2C19 metabolisms were compared. Binary logistic regression analysis was carried out to analyze the risk factors associated with MACEs and hemorrhagic events. Patients on ticagrelor had a greater number of bleeding complications compared to those on clopidogrel $(\mathrm{P}<0.001)$, with no difference in MACE between the two groups $(\mathrm{P}=0.399)$. The incidence of MACE was significantly higher in very slow metabolizing patients receiving clopidogrel $(\mathrm{P}<0.001)$ while the incidence of bleeding complications was significantly higher in fast metabolizing patients receiving ticagrelor $(\mathrm{P}<0.001)$. The regression analysis revealed that the $C Y P 2 C 19$ gene mutation, a dual-antiplatelet therapy, and a stroke history were all significantly associated with MACE. By contrast, a dual-antiplatelet therapy and a stroke history were significantly associated with bleeding events. Findings
\end{abstract}

Correspondence to: Dr Likun Ma, Department of Cardiology, The First Affiliated Hospital of USTC, Division of Life Science and Medicine, University of Science and Technology of China, $27 \mathrm{Lu}$ Jiang Road, Hefei, Anhui 230001, P.R. China

E-mail:1kma119@163.com

Key words: CYP2C19, clopidogrel, ticagrelor, heart disease, coronary atherosclerotic of the present study indicated that clopidogrel and ticagrelor were equally efficacious post-PCI. Efficacy of clopidogrel was reduced in patients with very slow CYP2C19 genotype while bleeding complications were higher in patients with fast CYP2C19 genotype receiving ticagrelor. CYP2C19 genotyping may be used to provide guidance to optimize individual antiplatelet treatment.

\section{Introduction}

Ticagrelor and clopidogrel are widely used as antiplatelet aggregation therapies in patients with coronary heart disease after percutaneous coronary interventions (PCIs). Clopidogrel is a prodrug converted to a pharmacologically active anti-platelet agent after metabolism by the CYP2C19 enzyme in the liver. However, in clinical practice, some patients do not achieve the desired anti-platelet action, and some may even show complete clopidogrel resistance resulting in severe adverse events including stent thrombosis, re-myocardial infarction, or death (1). Drug resistance has been attributed to CYP2C19 mutations, which mainly comprise the CYP2C19*2 and CYP2C19*3 alleles. Both of these mutant alleles can cause a decrease or complete loss of the CYP2C19 enzyme activity, influencing the efficacy of clopidogrel $(2,3)$. The US Food and Drug Administration advises clinicians that a detection of CYP2C19 genotype and platelet function may be carried out if poor response to clopidogrel is noted. Clinical guidelines in Europe and China have also been modified for the detection of CYP2C19 genotype and platelet function in patients undergoing coronary stent implantations. However, the actual clinical significance of the test results and of the following treatment adjustment, remain unclear $(4,5)$. The frequency of CYP2C19*2 and CYP2C19*3 mutations in the Asian population is estimated to be $57 \%$ (6). With the incidence of coronary heart disease and PCI surgery increasing annually, a higher number of Asian patients are expected to experience major cardiac adverse events (MACE) due to mutations in the CYP2C19 gene (7).

Ticagrelor is a new type of oral anti-platelet drug that can reversibly bind to adenosine receptors and exerts its anti-platelet action without in vivo metabolism. When compared with clopidogrel, ticagrelor has stronger anti-platelet aggregation effects; 
however, the risk of bleeding is also relatively higher. Due to the high cost and greater risk of hemorrhage, the discontinuation rate of ticagrelor is higher than that of clopidogrel.

The aim of the present study was to determine whether the antiplatelet drug regimen can be optimized by testing patients for the CYP2C19 genotype. Thus, we compared the safety and efficacy of clopidogrel vs. ticagrelor when used in patients with coronary heart disease undergoing PCI and assessed possible associations between the $C Y P 2 C 19$ gene polymorphism and the clinical outcomes after each treatment.

\section{Materials and methods}

Patients. A total of 971 patients with coronary heart disease who underwent hospitalization and PCI surgery at the First Affiliated Hospital of University of Science and Technology of China between April 2016 and May 2017 were enrolled. Of the 971 patients, 670 were men while 301 were women. Admission criteria for the study included: i) patients with coronary angiography-confirmed coronary heart disease and ii) with stent implantation. We excluded patients with i) indications for ticagrelor and aspirin or clopidogrel contraindications (including patients with severe liver and kidney dysfunction or active bleeding); ii) those with coagulopathy or surgical procedures within 30 days of the PCI, history of gastrointestinal bleeding within 6 months, and history of intracranial hemorrhage; and iii) patients with malignant tumors.

The local ethics committee of the University of Science and Technology of China approved the study. Written informed consent was obtained from all of the patients.

Methods. Patients were divided into clopidogrel and ticagrelor groups according to the oral antiplatelet drug used post-surgery. Patients in the clopidogrel group received postoperative oral clopidogrel $(75 \mathrm{mg})$ once daily combined with aspirin $(0.1 \mathrm{~g})$ once a day; and those in the ticagrelor group received postoperative oral ticagrelor $(90 \mathrm{mg})$ twice daily combined with aspirin $(0.1 \mathrm{~g})$ once a day.

CYP2C19 genotype determination. The CYP2C19 gene test chip kits (Shanghai Baiao Technology) were used for genotype detection of the entire sample. EDTA anticoagulant tubes were used to collect $2 \mathrm{ml}$ of venous blood samples, and each tube was then fully mixed to avoid coagulation or hemolysis and stored at $-20^{\circ} \mathrm{C}$. Within one week the sample was extracted for DNA, and the extracted sample was tested by $1.0 \%$ agarose gel electrophoresis, the DNA electrophoresis bands were clean and neat, and the fluorescent signal was relatively strong. The full DNA was subjected to PCR amplification, the genotype was detected by gene chip hybridization, and the CYP2C19 genotype was determined according to the arrangement order of the sequence of gene loci on the chip. The CYP2C19 gene type was divided according to the population's metabolic kinetics of clopidogrel: the wildtype as fast metabolizing (CYP2C19*1/*1); the mutant heterozygous gene as slow metabolizing (CYP2C19*1/*2, CYP2C19*1/*3); and the homozygous mutants as very slow metabolizing (CYP2C19*2/2*, CYP2C19*2/3*, CYP2C19*3/3*). Patients were classified as fast metabolizers, slow metabolizers, or very slow metabolizers based on the CYP2C19 gene type.
Follow-up. One year after administration of the drugs, all 971 patients were followed up via either telephone calls or outpatient visits. End-points were MACE and bleeding events. MACEs were defined as cardiac death, stent thrombosis, acute myocardial infarction, recurrent angina pectoris, and target vessel revascularizations. Bleeding events were classified as severe bleeding (lethal or clinically significant bleeding, bleeding that required blood transfusion or hospitalization such as cerebral hemorrhage or gastrointestinal bleeding); moderate bleeding (bleeding not requiring blood transfusion or hospitalization); and mild bleeding (bleeding gums or subcutaneous hemorrhages $<2 \mathrm{~mm}$ in diameter on the mucosa, skin, nose or other sites).

Statistical analysis. The incidence of MACE and bleeding events in the clopidogrel-treated and ticagrelor-treated groups was compared. Additionally, we compared outcomes in patients with fast, slow, and very slow CYP2C19 metabolisms. SPSS 22.0 software was used for data processing. Continuous data were expressed as mean \pm standard deviation (SD) and t-tests or one-way ANOVA (analysis of variance) was employed for comparisons between groups. Significant differences on ANOVA were further analyzed by Tukey's post-hoc Honestly Significant Difference test. The categorical data were represented by the number of cases and percentages, and the Chi-square test was used for comparisons between groups. A binary logistic regression analysis was applied to analyze the risk factors associated with MACEs and hemorrhagic events. Intercept (B) with standard error (SE) along with odds ratios (OR) and 95\% confidence intervals (CI) were calculated for each predictor variable. $\mathrm{P}<0.05$ was considered statistically significant.

\section{Results}

Basic clinical characteristics. Of the 971 patients who met the inclusion criteria, 670 were men while 301 were women. After CYP2C19 genotype analysis, we categorized 370 patients as fast metabolizers, 472 as slow metabolizers, and 129 as very slow metabolizers. Table I shows the basic clinical characteristics of patients. We determined antiplatelet treatment plans according to the genotyping results and the clinics. As a result, a total of 724 patients received clopidogrel, while 247 patients received ticagrelor. The number of patients with fast metabolizing, slow metabolizing, and very slow metabolizing CYP2C19 genotype in the clopidogrel group were 325,345 and 54, respectively. The corresponding number of patients in the ticagrelor group were 45,127 and 75 .

Comparison of endpoints in the clopidogrel and ticagrelor groups. We found no statistically significant difference in the 1-year MACEs between clopidogrel and ticagrelor groups $(\mathrm{P}=0.399)$. However, the incidence of bleeding was significantly higher with ticagrelor (19.82\%) than with clopidogrel (9.20\%) $(\mathrm{P}<0.001$; Table II).

Table III shows the incidence of MACEs and bleeding events in the patients with fast, slow, and very slow metabolizing CYP2C19 genotype in the clopidogrel-treated and ticagrelor-treated groups. In the clopidogrel group, the CYP2C19 genotype influenced the incidence of MACEs 
Table I. Clinical characteristics of patients classified according to CYP2C19 genotype.

\begin{tabular}{|c|c|c|c|c|}
\hline Variables & $\begin{array}{l}\text { Fast metabolizing } \\
\qquad(\mathrm{n}=370)\end{array}$ & $\begin{array}{l}\text { Slow metabolizing } \\
\qquad(\mathrm{n}=472)\end{array}$ & $\begin{array}{l}\text { Very slow metabolizing } \\
\qquad(\mathrm{n}=129)\end{array}$ & P-value ${ }^{a}$ \\
\hline Age $($ mean \pm SD) & $65.33 \pm 11.61$ & $65.76 \pm 11.98$ & $66.06 \pm 12.29$ & 0.791 \\
\hline Gender (male) & $258(69.73 \%)$ & $320(67.80 \%)$ & $92(71.32 \%)$ & 0.692 \\
\hline $\mathrm{BMI}\left(\mathrm{kg} / \mathrm{cm}^{2}\right.$, mean $\left.\pm \mathrm{SD}\right)$ & $24.17 \pm 3.65$ & $24.35 \pm 3.27$ & $24.97 \pm 3.50$ & 0.104 \\
\hline Smoking $(\mathrm{n}, \%)$ & $93(25.14 \%)$ & $109(23.09 \%)$ & $29(22.48 \%)$ & 0.734 \\
\hline Drinking $(\mathrm{n}, \%)$ & $53(14.32 \%)$ & $83(17.58 \%)$ & $18(13.95 \%)$ & 0.357 \\
\hline Hypertension (n, \%) & $232(62.70 \%)$ & $286(60.59 \%)$ & $82(63.57 \%)$ & 0.745 \\
\hline Diabetes $(\mathrm{n}, \%)$ & $84(22.70 \%)$ & $122(25.85 \%)$ & $40(31.01 \%)$ & 0.164 \\
\hline Cerebral infarction $(\mathrm{n}, \%)$ & $44(11.89 \%)$ & $71(15.04 \%)$ & $27(20.93 \%)$ & 0.047 \\
\hline Family history (n, \%) & $6(1.62 \%)$ & $9(1.91 \%)$ & $3(2.33 \%)$ & 0.875 \\
\hline ACEI/ARB (n, \%) & $151(40.81 \%)$ & $189(40.04 \%)$ & $49(37.98 \%)$ & 0.853 \\
\hline$\beta-\mathrm{BR}(\mathrm{n}, \%)$ & $202(54.59 \%)$ & $261(55.29 \%)$ & $60(46.51 \%)$ & 0.194 \\
\hline $\mathrm{CCB}(\mathrm{n}, \%)$ & $83(22.43 \%)$ & $111(23.52 \%)$ & $31(24.03 \%)$ & 0.905 \\
\hline Statins $(\mathrm{n}, \%)$ & $352(95.14 \%)$ & $461(97.67 \%)$ & $123(95.35 \%)$ & 0.110 \\
\hline PPI $(n, \%)$ & $122(32.98 \%)$ & $159(33.69 \%)$ & $52(40.31 \%)$ & 0.296 \\
\hline \multicolumn{5}{|l|}{ Auxiliary inspection } \\
\hline LVEF\% (mean \pm SD) & $59.44 \pm 11.67$ & $59.76 \pm 11.60$ & $57.39 \pm 13.37$ & 0.289 \\
\hline $\begin{array}{l}\text { Serum creatinine }(\mu \mathrm{mol} / \mathrm{l} \\
\text { mean } \pm \mathrm{SD})\end{array}$ & $78.60 \pm 33.99$ & $79.32 \pm 35.91$ & $81.46 \pm 36.55$ & 0.744 \\
\hline Hemoglobin $(\mathrm{g} / \mathrm{l}$, mean $\pm \mathrm{SD})$ & $129.22 \pm 16.85$ & $127.95 \pm 16.78$ & $127.70 \pm 17.44$ & 0.489 \\
\hline Platelet count $\left(10^{9} / 1\right.$, mean $\left.\pm \mathrm{s}\right)$ & $198.23 \pm 61.41$ & $205.06 \pm 65.66$ & $201.12 \pm 58.10$ & 0.295 \\
\hline $\mathrm{PT}(\mathrm{s}$, mean $\pm \mathrm{SD})$ & $11.94 \pm 2.91$ & $11.87 \pm 3.27$ & $11.78 \pm 2.02$ & 0.898 \\
\hline APTT $(\mathrm{s}$, mean $\pm \mathrm{SD})$ & $36.34 \pm 13.51$ & $36.44 \pm 14.22$ & $36.75 \pm 16.34$ & 0.968 \\
\hline INR $(\mathrm{s}$, mean $\pm \mathrm{SD})$ & $0.95 \pm 0.29$ & $0.94 \pm 0.32$ & $0.94 \pm 0.20$ & 0.952 \\
\hline
\end{tabular}

$\mathrm{n}$, Number of patients; s, seconds; SD, standard deviation; BMI, body mass index; ACEI, angiotensin-converting enzyme inhibitors; ARB, angiotensin receptor blockers; $\beta$-BR, $\beta$-blockers; CCB, calcium channel blockers; PPI, proton pump inhibitors; LVEH, left ventricular ejection fraction; PT, prothrombin time; APTT, activated partial thromboplastin time; INR, international normalization ratio; \%, percentage. ${ }^{a} \mathrm{One}-\mathrm{way}$ ANOVA or Chi-square test.

Table II. Comparison of MACE events and bleeding rates between the two groups at 1 year follow-up.

\begin{tabular}{lccr}
\hline Variables & Clopidogrel $(\mathrm{n}=724)$ & Ticagrelor $(\mathrm{n}=247)$ & $\chi^{2}$ \\
\hline MACE & $115(17.22 \%)$ & $30(14.71 \%)$ & 0.710 \\
Bleeding & $56(9.20 \%)$ & $43(19.82 \%)$ & 17.106 \\
\hline
\end{tabular}

significantly. The incidence of MACE was significantly higher in patients with very slow metabolizing type $(40.82 \%)$ than in those with slow metabolizing (18.84\%) and fast metabolizing $(9.23 \%)$ types $(\mathrm{P}<0.001)$. However, we found no statistically significant differences in terms of the incidence of bleeding in the three CYP2C19 subgroups of clopidogrel $(\mathrm{P}=0.888)$. In the ticagrelor group, the incidence of MACEs amongst the three CYP2C19 subgroups were similar $(\mathrm{P}=0.725)$. However, the patients with bleeding events were more numerous among the fast metabolizers $(35.55 \%)$ than among the slow (14.96\%) and very slow $(10.66 \%)$ metabolizers $(\mathrm{P}=0.001)$. All hemorrhagic events in the ticagrelor group were mild bleeding events with no cases of moderate or severe hemorrhages. Further subgroup analyses demonstrated that the incidence of angina pectoris in the clopidogrel group was significantly different among fast, moderate, and very slow metabolizers $(6.55,10.62$ and $40.82 \%$, respectively; $\mathrm{P}<0.001)$.

Comparison of endpoints in different CYP2C19 genotypes. Table IV shows the incidence of MACEs and bleeding events in patients with different CYP2C19 genotypes. Fast CYP2C19 metabolizers experienced significantly fewer MACEs (10\%) than slow (16.73\%) and very slow CYP2C19 metabolizers $(22.48 \%)(\mathrm{P}=0.0008)$.

The number of deaths $(\mathrm{P}=0.013)$ and bleeding events $(\mathrm{P}<0.001)$ were significantly higher in fast metabolizers on 


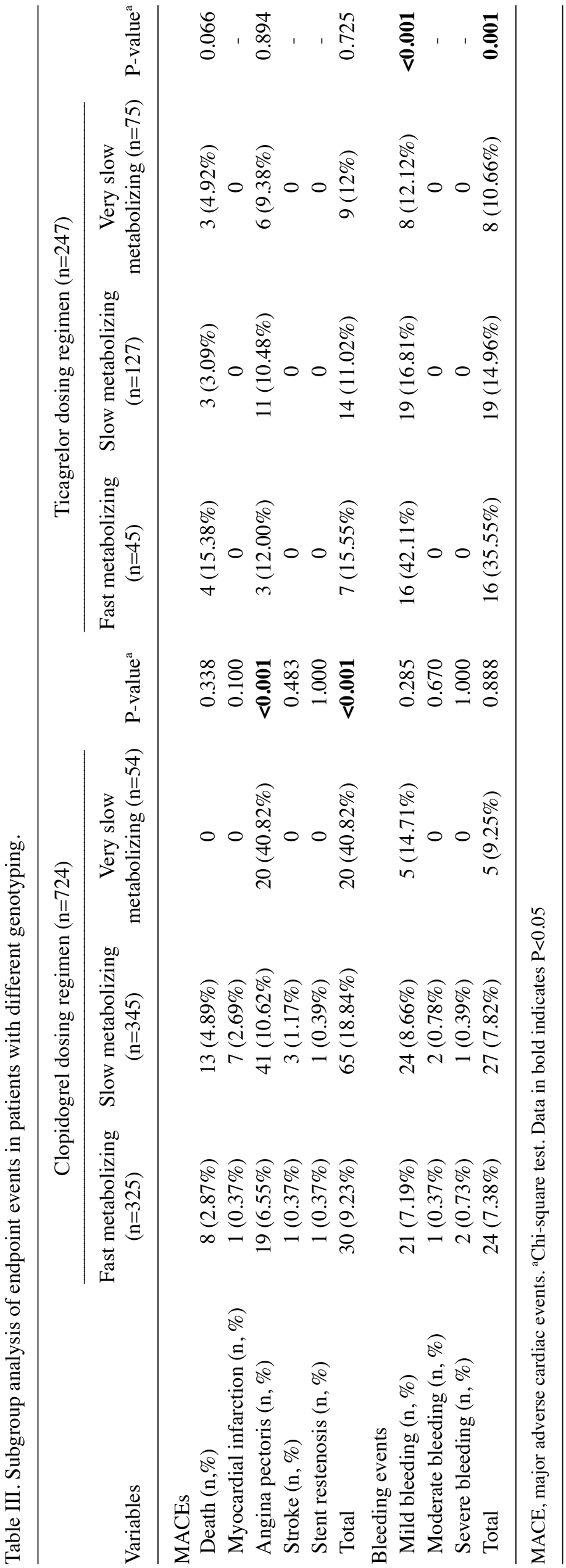




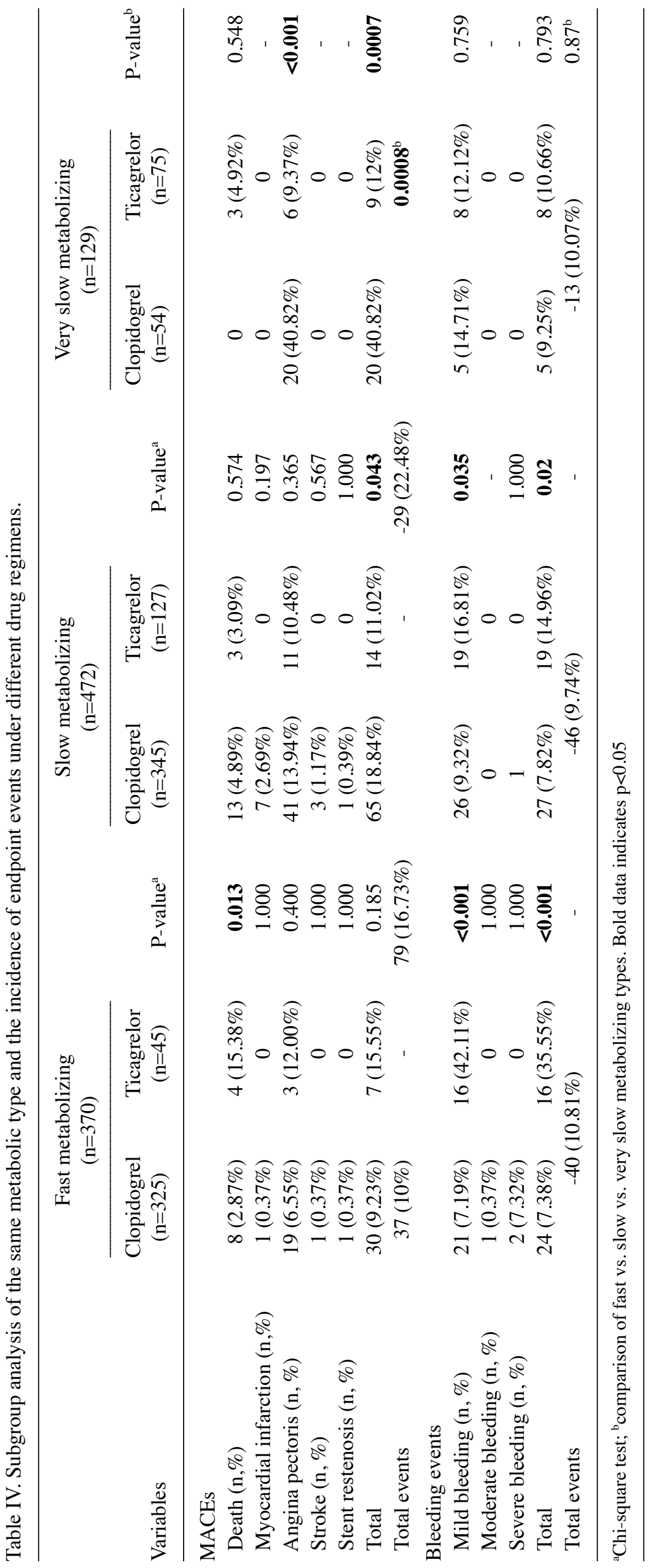


Table V. Binary logistic regression analysis (MACE).

\begin{tabular}{|c|c|c|c|c|c|c|}
\hline Variables & B & SE & wald & df & OR $(95 \% \mathrm{CI})$ & P-value \\
\hline CYP2C19 gene mutation & 0.599 & 0.150 & 16.047 & 1 & $1.821(1.358,2.441)$ & $<0.001$ \\
\hline Double antiplatelet treatment & -0.562 & 0.250 & 5.038 & 1 & $0.570(0.349,0.931)$ & 0.025 \\
\hline Age & 0.004 & 0.009 & 0.174 & 1 & $1.004(0.986,1.022)$ & 0.676 \\
\hline Gender & -0.277 & 0.241 & 1.323 & 1 & $0.758(0.472,1.216)$ & 0.250 \\
\hline BMI & 0.037 & 0.029 & 1.631 & 1 & $1.038(0.980,1.098)$ & 0.202 \\
\hline Smoking & -0.037 & 0.294 & 0.016 & 1 & $0.964(0.542,1.714)$ & 0.900 \\
\hline Drinking & -0.032 & 0.333 & 0.009 & 1 & $0.968(0.504,1.860)$ & 0.923 \\
\hline Hypertension & -0.135 & 0.214 & 0.394 & 1 & $0.874(0.574,1.331)$ & 0.530 \\
\hline Stroke & 0.768 & 0.242 & 10.097 & 1 & $2.156(1.342,3.462)$ & 0.001 \\
\hline Diabetes & -0.030 & 0.215 & 0.020 & 1 & $0.970(0.637,1.478)$ & 0.887 \\
\hline Family history & 0.423 & 0.619 & 0.466 & 1 & $1.527(0.453,5.140)$ & 0.495 \\
\hline Platelet count & -0.002 & 0.002 & 1.050 & 1 & $0.998(0.995,1.001)$ & 0.306 \\
\hline Hemoglobin & -0.002 & 0.006 & 0.106 & 1 & $0.998(0.987,1.010)$ & 0.744 \\
\hline ACEI/ARB & -0.016 & 0.204 & 0.006 & 1 & $0.984(0.660,1.469)$ & 0.939 \\
\hline$\beta$ Receptor blocker & -0.245 & 0.197 & 1.541 & 1 & $0.783(0.532,1.152)$ & 0.214 \\
\hline $\mathrm{CCB}$ & -0.043 & 0.237 & 0.033 & 1 & $0.958(0.603,1.523)$ & 0.856 \\
\hline Statins & -0.869 & 0.476 & 3.374 & 1 & $0.419(0.166,1.060)$ & 0.066 \\
\hline PPI & -0.197 & 0.206 & 0.907 & 1 & $0.822(0.548,1.231)$ & 0.341 \\
\hline
\end{tabular}

SE, Standard Error; OR, Odds ratio, BMI, body mass index; ACEI, angiotensin-converting enzyme inhibitors; ARB, angiotensin receptor blockers; CCB, calcium channel blockers; PPI, proton pump inhibitors; CI, confidence interval. Data in bold indicates $\mathrm{P}<0.05$.

ticagrelor than in those on clopidogrel. In slow metabolizers, the incidence of MACEs was higher in those on clopidogrel than in those of ticagrelor $(\mathrm{P}=0.043)$, while more patients experienced bleeding events with ticagrelor than with clopidogrel $(\mathrm{P}=0.02)$. For very slow metabolizers, significantly more patients on clopidogrel experienced MACEs than those on ticagrelor $(\mathrm{P}=0.0007)$, while the incidences of bleeding were similar with either drug $(\mathrm{P}=0.793)$.

Logistic regression analysis. The binary logistic regression analysis was used to assess CYP2C19 gene mutation, double-antiplatelet treatment regimen $(0=$ clopidogrel, $1=$ ticagrelor), age, sex, smoking history, drinking history, hypertension, stroke, diabetes, family history, platelet count, hemoglobin concentration, and concomitant medications (ACEI/ARB, $\beta$-blockers, CCB, statins, or PPI). The results showed that $C Y P 2 C 19$ gene mutations, double-antiplatelet treatment regimen, and stroke history were significantly associated with MACE, CYP2C19 gene mutation and stroke history were positively correlated with MACE $(\mathrm{P}<0.001$, $\mathrm{P}=0.001)$; and double-antibody treatment regimen $(0=$ clopidogrel, $1=$ ticagrelor) was negatively correlated with MACE $(\mathrm{P}=0.025$; Table $\mathrm{V})$.

A binary logistic regression analysis of bleeding events showed that the double-antiplatelet regimen and a stroke history were significantly associated with bleeding events, with a positive correlation $(\mathrm{P}<0.001)$ for double-antiplatelet regimen ( $0=$ clopidogrel, $1=$ ticagrelor) and bleeding events; and negative correlation for the history of stroke and the occurrence of bleeding events $(\mathrm{P}=0.008$; Table VI).

\section{Discussion}

European, American and Chinese guidelines for the treatment of patients with acute coronary syndrome have preferred treatment with ticagrelor and the status of clopidogrel as a dual antiplatelet therapy has been lost. However, we found no statistically significant differences in terms of the 1-year MACE incidence between the patients on clopidogrel and those on ticagrelor in our observational study. The bleeding incidences did differ significantly between the two groups (19.82\% in those on ticagrelor vs. 9.2\% in those on clopidogrel, $\mathrm{P}<0.001)$. The PLATO study demonstrated that ticagrelor reduces MACE, but the reduction seems to apply only after 30 days (7). In 2017, after adjusting for the propensity score, Vercellino et al (8) found there was no difference in the reduction of MACE between ticagrelor and clopidogrel within one year. Findings of that study are similar to our observations. The antiplatelet aggregation of ticagrelor was not affected by the CYP2C19 genotype, and the risk of bleeding was significantly increased in patients on ticagrelor compared to those on clopidogrel (9). In the clopidogrel group, the incidence of MACE differed significantly according to the genotyping. Patients with fast metabolizing CYP2C19 genotype had the least number of MACE while patients with very slow CYP2C19 genotype experienced the highest number of MACE in the present study. In terms of the CYP2C19 genotype, when comparing very slow with fast metabolizers, the concentration of effective active drugs in plasma was significantly reduced in the latter, so the anti-platelet aggregation effect was low $(3,10)$. Therefore, we selected clopidogrel as 
Table VI. Binary logistic regression analysis (bleeding events).

\begin{tabular}{|c|c|c|c|c|c|c|}
\hline Variables & B & SE & wald & df & OR $(95 \% \mathrm{CI})$ & P-value \\
\hline CYP2C19 gene mutation & -0.176 & 0.177 & 0.994 & 1 & $0.839(0.593,1.185)$ & 0.319 \\
\hline Double antiplatelet treatment & 1.064 & 0.253 & 17.749 & 1 & $2.897(1.766,4.753)$ & $<0.001$ \\
\hline Age & -0.008 & 0.010 & 0.579 & 1 & $0.992(0.972,1.013)$ & 0.447 \\
\hline Gender & 0.176 & 0.274 & 0.412 & 1 & $1.192(0.697,2.041)$ & 0.521 \\
\hline BMI & -0.004 & 0.036 & 0.013 & 1 & $0.996(0.929,1.068)$ & 0.909 \\
\hline Smoking & -0.133 & 0.353 & 0.142 & 1 & $0.875(0.438,1.749)$ & 0.706 \\
\hline Drinking & 0.145 & 0.396 & 0.134 & 1 & $1.156(0.532,2.512)$ & 0.714 \\
\hline Hypertension & -0.195 & 0.250 & 0.612 & 1 & $0.822(0.504,1.342)$ & 0.434 \\
\hline Stroke & -0.814 & 0.309 & 6.958 & 1 & $0.443(0.242,0.811)$ & 0.008 \\
\hline Diabetes & 0.189 & 0.807 & 0.055 & 1 & $1.208(0.249,5.875)$ & 0.814 \\
\hline Family history & -0.293 & 0.384 & 0.582 & 1 & $0.746(0.351,1.584)$ & 0.446 \\
\hline Platelet count & -0.002 & 0.002 & 1.692 & 1 & $0.998(0.994,1.001)$ & 0.193 \\
\hline Hemoglobin & -0.005 & 0.007 & 0.544 & 1 & $0.995(0.982,1.008)$ & 0.461 \\
\hline ACEI/ARB & 0.240 & 0.237 & 1.025 & 1 & $1.271(0.799,2.024)$ & 0.311 \\
\hline$\beta$ Receptor blocker & -0.405 & 0.229 & 3.146 & 1 & $0.667(0.426,1.044)$ & 0.076 \\
\hline $\mathrm{CCB}$ & 0.136 & 0.279 & 0.238 & 1 & $1.146(0.663,1.979)$ & 0.625 \\
\hline Statins & -0.727 & 0.459 & 2.507 & 1 & $0.484(0.197,1.189)$ & 0.113 \\
\hline PPI & -0.514 & 0.250 & 4.215 & 1 & $0.598(0.366,0.977)$ & 0.040 \\
\hline
\end{tabular}

SE, standard error; OR, odds ratio, BMI, body mass index; ACEI, angiotensin-converting enzyme inhibitors; ARB, angiotensin receptor blockers; CCB, calcium channel blockers; PPI, proton pump inhibitors; CI, confidence interval. Data in bold indicates $\mathrm{P}<0.05$.

a PCI antiplatelet therapy. Increased MACE was present in the very slow and slow metabolizers than in the fast metabolizers $(11,12)$.

Findings have shown that ticagrelor has lower MACE incidence rates in patients with very slow and moderate CYP2C19 metabolism than clopidogrel, while MACE events in patients without CYP2C19 mutation are similar to those of slow metabolizers (11). However, our subgroup analysis showed that fast metabolizers had significantly different rates of death depending on their treatment with either clopidogrel $(2.87 \%)$ or ticagrelor $(15.38 \% ; \mathrm{P}=0.013)$, and that mild bleeding incidences also differed significantly (7.19\% of those on clopidogrel vs. $42.11 \%$ of those on ticagrelor, $\mathrm{P}<0.001)$. In fast metabolizers, the mortality rate of those on ticagrelor was higher than that of those on clopidogrel. This may be due to the number of cases being less for fast metabolizers on ticagrelor than for those on clopidogrel, and due to the fact that patients with coronary lesions often have left main, multi-vessel disease, severe calcification, and other complex lesions (11). In the clinic, Chinese physicians often use the strong anti-platelet aggregation drug ticagrelor despite the patients being fast metabolizers, because these patients have a higher incidence rate of MACE $(3,7)$. In our study, the patients with very slow and slow CYP2C19 metabolism on ticagrelor had a lower MACE rate compared to those on clopidogrel. In patients with very slow CYP2C19 metabolism, the MACE rate was statistically significantly lower in patients on ticagrelor than in those on clopidogrel. The results of the current study are consistent with previous findings (13).
The association between $C Y P 2 C 19$ gene mutations and cardiovascular MACE rates is debatable, but different studies have selected different patient populations with different risk factors $(14,15)$. The CYP2C19 gene polymorphism is not the only factor affecting the individual response to clopidogrel; age, body mass index, blood lipid levels, combined medication, and clopidogrel doses can also affect the patient's platelet activity (16). ACS patients have benefited significantly from anti-platelet aggregation therapy based on CYP2C19 gene variants (17).

The present study has some limitations including a relatively small sample size and a retrospective single-centered nature, and RCT studies are needed on different types of patients.

Within the purview of the limitations of the present study, our results indicate that both clopidogrel and ticagrelor may be equally efficacious in coronary heart disease patients undergoing PCI. However, efficacy of clopidogrel seems to be reduced in patients with very slow CYP2C19 genotype while bleeding complications tend to be higher in patients with fast CYP2C19 genotype receiving ticagrelor. CYP2C19 genotyping may be used as a guide to optimize individual antiplatelet treatment in patients undergoing PCI to improve efficacy and reduce complications. Further studies in the form of RCTs are required to provide robust evidence.

\section{Acknowledgements}

Not applicable. 


\section{Funding}

This study was supported by the National Natural Science Foundation of China (grant no. 81870192) and the science project of Anhui Provincial Cardiovascular Institute (grant no. KF2018007) and 'Borrow to transfer to supplement' project of Hefei independent innovation policy (grant no. J2019Y02).

\section{Availability of data and materials}

The datasets used and/or analyzed during the current study are available from the corresponding author on reasonable request.

\section{Authors' contributions}

DY and LM designed the study and provided study materials. LM, JZ, LL, WY and XY were responsible for the collection and assembly of the data, data analysis and interpretation. DY was involved in the writing of the manuscript. LM was involved in the editing of the manuscript. All authors have read and approved the final manuscript.

\section{Ethics approval and consent to participate}

This research was approved by the Ethics Committee of Anhui provincial hospital (approval no. 2019 P 029). Informed consent was collected from patients.

\section{Patient consent for publication}

Not applicable.

\section{Competing interests}

The authors declare that they have no competing interests.

\section{References}

1. Mejin M, Tiong WN, Lai LYH, Tiong LL, Bujang AM, Hwang SS, Ong TK and Fong AY: CYP2C19 genotypes and their impact on clopidogrel responsiveness in percutaneous coronary intervention. Int J Clin Pharm 35: 621-628, 2013.

2. Oestreich JH, Best LG and Dobesh PP: Prevalence of CYP2C19 variant alleles and pharmacodynamic variability of aspirin and clopidogrel in Native Americans. Am Heart J 167: 413-418, 2014

3. Shuldiner AR, O'Connell JR, Bliden KP, Gandhi A, Ryan K, Horenstein RB, Damcott CM, Pakyz R, Tantry US, Gibson Q, et al: Association of cytochrome P450 2C19 genotype with the antiplatelet effect and clinical efficacy of clopidogrel therapy. JAMA 302: 849-857, 2009.

4. Levine GN, Bates ER, Blankenship JC, Bailey SR, Bittl JA, Cercek B, Chambers CE, Ellis SG, Guyton RA, Hollenberg SM, et al: 2011 ACCF/AHA/SCAI Guideline for Percutaneous Coronary Intervention: A report of the American College of Cardiology Foundation/American Heart Association Task Force on Practice Guidelines and the Society for Cardiovascular Angiography and Interventions. Circulation 124: e574-e651, 2011.
5. Hamm CW, Bassand J-P, Agewall S, Bax J, Boersma E, Bueno H, Caso P, Dudek D, Gielen S, Huber K, et al; ESC Committee for Practice Guidelines: ESC Guidelines for the management of acute coronary syndromes in patients presenting without persistent ST-segment elevation: The Task Force for the management of acute coronary syndromes (ACS) in patients presenting without persistent ST-segment elevation of the European Society of Cardiology (ESC). Eur Heart J 32: 2999-3054, 2011.

6. Fricke-Galindo I, Céspedes-Garro C, Rodrigues-Soares F, Naranjo ME, Delgado Á, de Andrés F, López-López M, Peñas-Lledó E and LLerena A: Interethnic variation of CYP2C19 alleles, 'predicted' phenotypes and 'measured' metabolic phenotypes across world populations. Pharmacogenomics J 16: 113-123, 2016.

7. Sorich MJ, Rowland A, McKinnon RA and Wiese MD: CYP2C19 genotype has a greater effect on adverse cardiovascular outcomes following percutaneous coronary intervention and in Asian populations treated with clopidogrel: A meta-analysis. Circ Cardiovasc Genet 7: 895-902, 2014.

8. Vercellino M, Sànchez FA, Boasi V, Perri D, Tacchi C, Secco GG, Cattunar S, Pistis G and Mascelli G: Ticagrelor versus clopidogrel in real-world patients with ST elevation myocardial infarction: 1-year results by propensity score analysis. BMC Cardiovasc Disord 17: 97, 2017.

9. Wallentin L, Becker RC, Budaj A, Cannon CP, Emanuelsson H, Held C, Horrow J, Husted S, James S, Katus H, et al; PLATO Investigators: Ticagrelor versus clopidogrel in patients with acute coronary syndromes. N Engl J Med 361: 1045-1057, 2009.

10. Dayoub EJ, Seigerman M, Tuteja S, Kobayashi T, Kolansky DM, Giri $\mathbf{J}$ and Groeneveld PW: Trends in Platelet Adenosine Diphosphate P2Y12 Receptor Inhibitor Use and Adherence Among Antiplatelet-Naive Patients After Percutaneous Coronary Intervention, 2008-2016. JAMA Intern Med 178: 943-950, 2018.

11. Mega JL, Close SL, Wiviott SD, Shen L, Hockett RD, Brandt JT, Walker JR, Antman EM, Macias W, Braunwald E, et al: Cytochrome p-450 polymorphisms and response to clopidogrel. N Engl J Med 360: 354-362, 2009.

12. Mega JL, Simon T, Collet J-P, Anderson JL, Antman EM, Bliden K, Cannon CP, Danchin N, Giusti B, Gurbel P, et al: Reduced-function CYP2C19 genotype and risk of adverse clinical outcomes among patients treated with clopidogrel predominantly for PCI: A meta-analysis. JAMA 304: 1821-1830, 2010.

13. Mao L, Jian C, Changzhi L, Dan H, Suihua H, Wenyi T and Wei W: Cytochrome CYP2C19 polymorphism and risk of adverse clinical events in clopidogrel-treated patients: A meta-analysis based on 23,035 subjects. Arch Cardiovasc Dis 106: 517-527, 2013.

14. Chan NC, Eikelboom JW, Ginsberg JS, Lauw MN, Vanassche T, Weitz JI and Hirsh J: Role of phenotypic and genetic testing in managing clopidogrel therapy. Blood 124: 689-699, 2014.

15. Hulot J-S, Collet J-P, Silvain J, Pena A, Bellemain-Appaix A, Barthélémy O, Cayla G, Beygui $F$ and Montalescot G: Cardiovascular risk in clopidogrel-treated patients according to cytochrome P450 2C19*2 loss-of-function allele or proton pump inhibitor coadministration: A systematic meta-analysis. J Am Coll Cardiol 56: 134-143, 2010.

16. Frelinger AL III, Bhatt DL, Lee RD, Mulford DJ, Wu J, Nudurupati S, Nigam A, Lampa M, Brooks JK, Barnard MR, et al: Clopidogrel pharmacokinetics and pharmacodynamics vary widely despite exclusion or control of polymorphisms (CYP2C19, ABCB1, PON1), noncompliance, diet, smoking, co-medications (including proton pump inhibitors), and pre-existent variability in platelet function. J Am Coll Cardiol 61: 872-879, 2013.

17. Beitelshees AL, Voora D and Lewis JP: Personalized antiplatelet and anticoagulation therapy: Applications and significance of pharmacogenomics. Pharmgenomics Pers Med 8: 43-61, 2015. 